\title{
ACCIDENT COMPENSATION: THE ROLE OF INCENTIVES, CONSUMER CHOICE AND COMPETITION
}

\author{
Lewis Evans* and Neil Quigley**
}

In the 1990s, the insurance aspect, as opposed to the social welfare or more communitarian face of the Accident Compensation was prominent in public debate. In this paper, Professors Evans and Quigley argue that Accident Compensation is indeed more appropriately seen as an insurance scheme. As such they question the appropriateness of state monopoly provision, believing that competition would give both employers and workers greater choice.

\section{INTRODUCTION}

With the exception of the introduction of experience-rated premiums, the incorporation of the term "insurance" in the title of the 1992 legislation, ${ }^{1}$ and the short-lived reforms to the structure of workplace accident compensation in 1998, New Zealand's accident compensation scheme has continued to adhere to the principles laid down in the Woodhouse Report. ${ }^{2}$ In particular, public monopoly provision, comprehensive coverage and mandatory purchase, separation from other segments of the market for personal risk (where private insurance companies operate) and crosssubsidies between different categories of insured risk were explicit components of Woodhouse's conception of the scheme. Retention of these aspects of the scheme has been justified by the claim that accident compensation is a component of the social welfare net rather than an insurance scheme

* Professor of Economics, Victoria University of Wellington and Executive Director of the New Zealand Institute for the Study of Competition and Regulation.

** Professor of Economics and Pro-Vice Chancellor (International) Victoria University of Wellington. We thank Fleur Knowsley (ISCR Research Assistant, and Law Clerk, Kensington Swan) for her assistance with the preparation of this paper.

1 Accident Rehabilitation and Compensation Insurance Act 1992.

2 New Zealand Royal Commission of Inquiry into Compensation for Personal Injury Compensation for Personal Injury in New Zealand: Report of the Royal Commission of Inquiry (Government Printer, Wellington, 1967) [Woodhouse Report]. 
and that the social welfare approach is superior from the point of view of those covered by the scheme.

This paper reviews three of the economic issues raised by the structure of our accident compensation scheme: the role of incentives, the relationship with the broader insurance market and the costs of government monopoly provision. We use our analysis of these issues to consider the veracity of the claim that potential accident victims in New Zealand benefit from our adherence to the principles laid out by the Woodhouse Report. We conclude that the current structure of our scheme creates perverse incentives that substantially reduce its efficiency while also denying those covered by the scheme the potential benefits that would come from consumer choice among competing providers offering a broader range of risk products.

\section{INSURANCE}

The Woodhouse Report treats accidents as exogenous events: that is, it views the frequency of accidents as independent of the incentives facing workers and employers. Consequently, it argues that meeting the costs of accidents is a social responsibility not a matter for which individuals or employers should be required to obtain private insurance. For example, the Woodhouse Report describes the fundamental principle of community responsibility around which its recommendations are built: ${ }^{3}$

Just as a modern society benefits from the productive work of its citizens, so should society accept responsibility for those willing to work but prevented from doing so by physical incapacity. And, since we all persist in following community activities, which year by year exact a predictable and inevitable price in bodily injury, so should we all share in sustaining those who become the random but statistically necessary victims.

However, community responsibility is not a principle on which accident compensation must be built because accidents satisfy all of the important criteria required for the creation of a private insurance market:

- Accidents represent an insurable risk because they are more predictable in a large sample of the population than they are for any individual;

- The frequency and value of claims on the accident compensation scheme are affected by the incentives for investment in prevention and safety, as well as by the incentives of claimants and medical professionals to classify illness as resulting from an accident;

- The accident compensation scheme can be described in an insurance contract; and

- It is possible for multiple private insurers to provide the service, that is, there is no market failure which requires monopoly public sector provision.

3 Woodhouse Report, above, 40. 
Those who doubt the validity of these arguments need only look to the extensive evidence of successful private provision of workplace accident compensation in Australia and the United States for confirmation that monopoly public provision is unnecessary. ${ }^{4}$

Since accident insurance of the type provided by the New Zealand scheme forms part of the broader market for the insurance of personal risk, mandatory separation of accident insurance will raise the cost of obtaining personal risk insurance in certain circumstances. In particular, if there are economies of scope in the insurance of different types of personal risk, either because of common elements in the risk or common elements in the cover and benefits payable, then integration of accident risk into the broader insurance market will reduce the costs of insurance. In addition, the purchase of multiple lines of insurance from separate insurers increases transaction costs. This is particularly true when private insurance policies such as health and income protection have to be designed to complement the cover provided by ACC when it could instead be integrated into a single policy. Thus, the cost of providing insurance is reduced where cover for a range of different risks is provided by a single insurer, and in a competitive market these cost savings will be passed on to consumers. Consequently, consumers are made worse off by separation of accident insurance from the broader insurance market, and by provision of the insurance through a monopoly state supplier with no power to extend higher levels of, or other types of, insurance.

\section{INCENTIVES}

The incentives created by the existence of a no-fault, compulsory accident compensation scheme impact on the decisions made by both the insured parties and the insurer. The efficiency of the incentives associated with the scheme will have a major impact on the costs of providing the insurance and the benefits obtained by insured parties.

All insurance contracts create "moral hazard". 5 In respect of accident insurance, moral hazard arises from the fact that insurance reduces the incentives of the insured party to avoid the contingency insured against, and increases the incentives of the insured party to claim that an accident occurred when it did not. Moral hazard is reduced the higher is the co-insurance (share of the cost of the accident that is carried by the insured party).

4 See for example, Amy Finkelstein The Interaction of Partial Public Insurance Programs and Residual Private Insurance Markets: Evidence from the United States Medicare Program (National Bureau of Economic Research Working Paper Series, number 9031, 2002) and also Munich Re Group Workers Compensation: Analysis of Private and Public Schemes (Munich Re Group, Munich, 2001) available at $<\mathrm{http}: / /$ www.munichre.com $>$.

5 In the insurance literature moral hazard refers to the tendency of people with insurance to reduce the care that they take to avoid the contingency insured against. In the economics literature moral hazard is used in a consistent but broader way, and refers to all post-contractual opportunism by one of the parties to the contract. 


\section{A The Incentives of the Self-Employed}

An example of the impact of moral hazard is provided by the fact that self-employed workers have fewer accidents (see Table 1).

TABLE 1: INJURY PER 100,000 WORKERS - SELF EMPLOYED VERSUS EMPLOYED (2000/2001)

\begin{tabular}{|l|c|c|c|c|}
\hline & Agriculture & Manufacturing & Construction & Transport \\
\hline Self-Employed & 13,036 & 5,462 & 3,623 & 1,665 \\
\hline Employed & 16,772 & 17,127 & 6,322 & 13,488 \\
\hline \% Difference & $28.7 \%$ & $213.6 \%$ & $74.5 \%$ & $710.1 \%$ \\
\hline
\end{tabular}

Source: Accident Compensation Corporation

Recent European research (detailed in Table 2 below) confirms that overall there is a tendency for self-employed individuals to recuperate quicker than their employed counterparts, which in turn confirms the presence of the incentives for self-employed workers to internalise the costs of injuries.

TABLE 2:

AVERAGE NUMBER OF DAYS ABSENCE OVER LAST 12 MONTHS

\begin{tabular}{|l|c|c|c|}
\hline Reason for Absence & All Workers & $\begin{array}{c}\text { Self-Employed } \\
\text { Workers }\end{array}$ & Difference \\
\hline Occupational Accidents & 1.26 & 0.76 & $65.8 \%$ \\
\hline Work-related health problems & 1.80 & 0.86 & $109.3 \%$ \\
\hline Non work related health problems & 4.2 & 2.24 & $87.5 \%$ \\
\hline
\end{tabular}

Source: Pascal Paoli and Damien Merllie Third European Survey on Working Conditions 2000.

There are a number of potential explanations for these figures, but all point towards perverseincentives created by accident compensation insurance. The higher accident rate for employees may result from the fact that the greater compensation and preferential health benefits received via $\mathrm{ACC}^{6}$ provide employees with incentives to claim all injuries as accidents regardless of their actual cause. However this explanation should apply to both employees and self-employed persons. Another

6 Treatment within the New Zealand health system is budget constrained and provided on a 'needs assessed' basis, as opposed to treatment within the ACC system, which is not budget constrained and based on an entitlement basis. Thus, typically an injured individual is likely to receive quicker treatment when claims are made via ACC, as opposed to the traditional health system. (Source: Ministry of Health). 
possibility is that there are genuinely more accidents involving employees, in which case employment environments for employed individuals are significantly less safe than those of their self-employed counterparts, or the more accident prone members of society self-select away from self-employment. Finally, but perhaps most importantly, the opportunity cost of being off work is much higher for a self-employed person than it is for an employee. The incentives resulting from the opportunity cost of time off work would explain not only the low accident rates among selfemployed, but also the relatively low accident rates among high income earners.

\section{B The Asymmetry Between Sickness and Accident Benefits}

Another example of inefficient incentives is the asymmetry between benefits for victims of illness and accident. Consider the example of a single 30 year old without children. If they suffer illness as a result of a gradual process, such as multiple sclerosis, and it results in them being unable to work 15 hours or more per week for a period of at least two years, they may be eligible for an invalid's benefit. ${ }^{7}$ This entitles them to $\$ 196.70$ per week. ${ }^{8}$ Alternatively, if the same person suffers from a temporary illness, such as glandular fever for a period of less than two years, they may be eligible for a sickness benefit ${ }^{9}$, which entitles them to $\$ 157.37$ per week. ${ }^{10}$ Now consider the situation of the same person who is injured due to an accident, and is unable to work as a consequence. Weekly compensation for personal injury under the Act entitles the accident victim to 80 per cent of their pre-injury earnings. The average weekly wages and salaries earned in New Zealand were $\$ 573$ per week before tax for the year ended 30 June 2001. ${ }^{11}$ After deducting tax, compensation provided to the average New Zealander under ACC would be $\$ 369$ per week. This equates to a 87.6 per cent increase on the amount received under an invalid's benefit and a 134.5 per cent increase on the amount received under a sickness benefit.

The asymmetry between sickness and accident benefits provides strong incentives to claim that any disability resulted from an accident. An example of how the incentives affect providers is shown by Figure 1 below. This purports to show that between 1992 and 1994 there was a dramatic (17.2 per cent) increase in the number of non-fatal injuries in New Zealand. This increase is, however, not due to an increase in the number of accidents: it can be explained by changes in institutional arrangements and their impact on incentives. The purchasing arrangements for ACC

7 Provided for under the Social Security Act 1964, s 40.

8 For entitlements, see Work and Income New Zealand Invalids Benefit (Work and Income New Zealand, Wellington, 2002) available at <http://www.winz.govt.nz/get_financial_assistance/benefits/ main_benefits/invalids_benefit.html>.

9 Provided for under the Social Security Act 1964, s 54.

10 Work and Income New Zealand, above

11 Statistics New Zealand Statistics New Zealand Household Economic Survey Year Ended 30 June 2001 (Statistics New Zealand, Wellington, 2001). 
Figure 1

Injury (Fatal and Non-Fatal) per 100,000 Persons in New Zealand 1988 - 1998

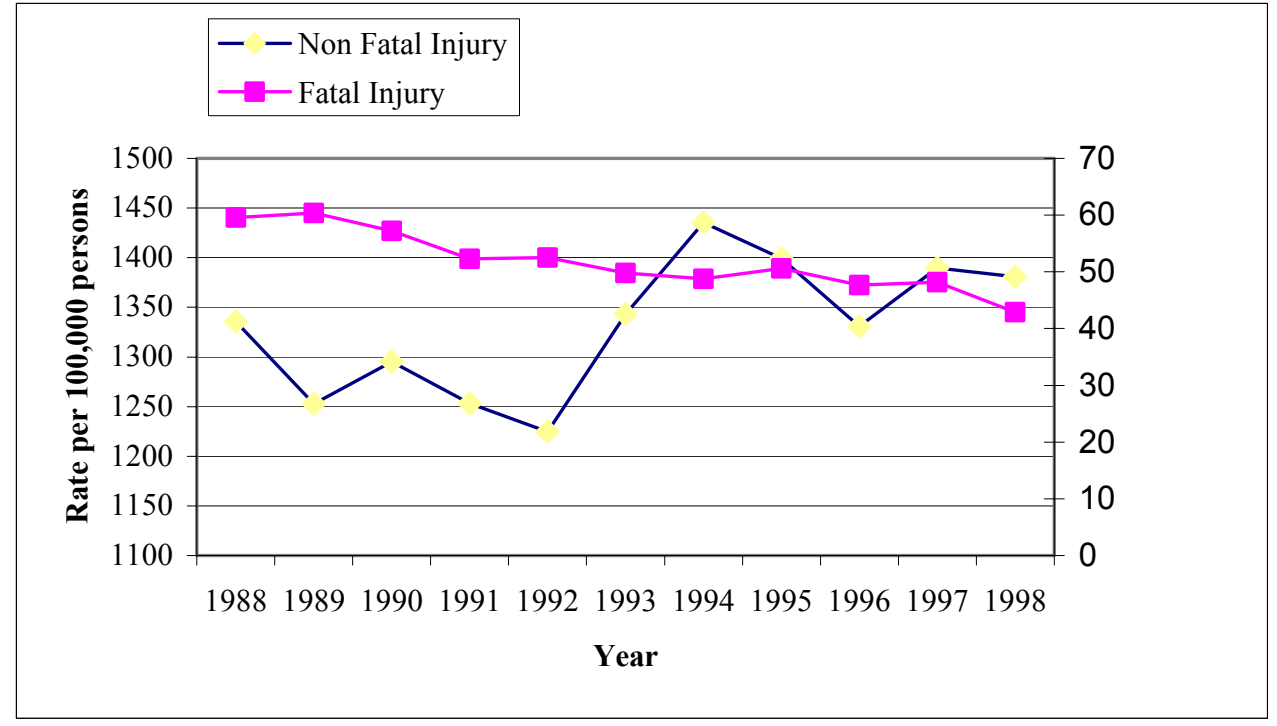

changed away from block funding to funding per accident reported. These institutional changes created an incentive for health providers to report more accidents or to code more accident causes.

\section{Consumer Choice}

New Zealand's ACC scheme is not voluntary: it provides for compulsory purchase of a standard policy. Consequently, this scheme rules out consumer choice. Indeed, consumer choice is so comprehensively excluded from the scheme that consumers are not permitted even to make choices about the level of insurance above a minimum required level of cover. In this section we explore the implications of the absence of consumer choice in the ACC scheme.

\section{The "Adequacy" of Entitlements}

In the event of a personal injury, which results in the claimant being "incapacitated" in that they are unable to engage in employment, in which they were employed before the personal injury occurred, ${ }^{12}$ the Act entitles the claimant to weekly compensation of 80 per cent of their pre-injury earnings. The Act and its accompanying regulations also provide for contributions to further

12 "Incapacity" in terms of the Injury Prevention, Rehabilitation and Compensation Act 2001 is defined in s 103(2). 
ancillary expenses in certain circumstances. Emergency care and ambulance care are paid in full by ACC. ${ }^{13}$ ACC will pay for acute public hospital admissions or non-urgent surgery, unless the claimant chooses a private provider who does not have a contract with ACC. ACC may also contribute towards the costs of visits by the claimant to his or her treatment provider and may contribute towards part of the fee for common types of treatment. Allowance is also made for contribution towards transport costs in certain specified circumstances, set out in the regulations to the Injury Prevention, Rehabilitation and Compensation Act 2001. The patient must be travelling a specified distance within a specified timeframe, or spending a certain amount on public transport per month in order to reach the nearest treatment provider. In such circumstances, ACC will pay a maximum of 28 cents per kilometre, if travelling by private motor vehicle, or the public transport fare.

Whether these benefits are considered "adequate" will depend very much on the propensity of each individual to bear the risk associated with the costs that are not covered by ACC. A single person with no mortgage might find 80 per cent of their pre-accident salary provides an adequate income during the period that they cannot work, but a family with children and a mortgage may much less easily absorb the 20 per cent reduction in post-accident income. In a market that provided choice to consumers, it would be possible for consumers to choose whether to insure 80 per cent or 90 per cent of their pre-accident income, and pay a premium commensurate with the level of cover that they chose. Similarly, the adequacy of the benefits will depend on whether the person suffering the accident expected to receive substantial salary increases in the near future, or was at a point of their career where they expected no salary increases or perhaps even to be made redundant.

The union movement regularly offers examples of situations in which the ACC benefits were manifestly inadequate to meet the costs necessarily associated with the treatment and rehabilitation of a person who suffered a workplace accident. ${ }^{14}$ Their approach is to argue that benefits and coverage should be increased across the board to resolve these problems of inadequate cover. This "all or nothing" solution is inappropriate precisely because some workers no doubt have a propensity to bear risk consistent with the current scheme, and would rather have higher wages rather than the higher ACC benefits suggested by union representatives. In addition, claims for higher benefits rarely take into account the fact that they will result in an increase in the moral hazard problems associated with the scheme by reducing co-insurance levels and thus giving some workers stronger incentives to report accidents and weaker incentives to avoid accidents. Better, in our view, would be a scheme that required a minimum level of coverage to be purchased but allowed consumer choice beyond that. This would mean that:

13 However, ACC will not foot the bill for an ambulance trip, if the claimant is dead on arrival.

14 See Ross Wilson "1990s - Decade of Change" (2003) 34 VUWLR 387. 
- Unions could negotiate higher levels of coverage, or coverage for events not required under the compulsory scheme, as part of their negotiations with the employer.

- Individuals could obtain higher levels of cover than the compulsory or collective contract provided if they wished to do so.

\section{COMPETITION}

\section{A Decentralisation, Incentives and Choice}

The ACC is a statutory monopoly provider of accident compensation insurance in New Zealand. A State monopoly is the ultimate form of centralised decision making. If decision-making were decentralised, there would be more focus on consumers being provided what they actually demanded because this is the basis upon which providers compete for market share. Suppliers would also be free to produce the mix of services they wanted to. In an environment with decentralised decision-making, both incentives and the discipline provided by competitive tension must be present. This would provide to consumers a menu of choices regarding their risk-based premiums and the extent of their cover. For example, in a private market insurance cover for illness or accident and insurance against income protection would be intrinsically linked, not separate as under ACC, and the choice of co-insurance level would be used to determine the premium that should be paid. 15

The provision of a menu of insurance options is in marked contrast to the absence of consumer choice associated with social welfare. The absence of choice in social welfare schemes follows from the fact that they are designed to provide social cohesion by setting minimum income levels for all members of society. They are explicitly not designed either to ensure against specific contingencies (it is the absence of adequate income for subsistence that is the trigger for a social welfare payment) or to provide adequate compensation for cost incurred or income foregone. Further, social welfare schemes financed from general taxation revenue have no feasible means of allowing members of society to choose higher compensation levels and pay higher taxes as a result: there is no necessary relation between taxes paid and expected benefits from social welfare schemes in any event.

\section{B Time Inconsistency and Government Provision}

The major problem with public monopoly provision of ACC is that it cannot be time consistent because no government can bind future governments. Thus, while full funding of claims is an

15 We note that the ACC has recently begun to offer self-employed persons a choice between the standard cover and a higher level of cover (at a higher premium). This provides just one example of the wide range of options that would become available to consumers if ACC or private insurers faced competitive pressure to meet the needs of consumers. However, the involvement of ACC does not solve the problem that the cover applies only to accidents rather than all causes. ACC involvement also raises concerns about the pricing of the cover given that ACC's power to levy premiums for the compulsory cover does provide it with the potential to cross-subsidise different lines of business. 
ongoing regulatory requirement of all private insurers, governments always have the option of looting a fully-funded scheme (for example, by declaring a contribution holiday). Similarly, governments may change entitlements even for existing beneficiaries, though this would constitute a breach of contract for a private insurer.

Charles Wilson ${ }^{16}$ provided support for the idea that government intervention in insurance would be Pareto improving in a situation where there was a pooling equilibrium with adverse selection in the private market. Wilson showed that by providing the pooling policy as a compulsory publicly run scheme, and allowing individuals to purchase supplementary insurance in the private market, there will always be a Pareto improvement. This theory however rests on the assumption that individuals can only purchase one insurance policy in the private market. Amy Finkelstein considers this point and concludes that: ${ }^{17}$

The government's capacity for affecting [a] Pareto improvement stems not from its unique capacity to compel participation in an insurance program, but merely from its introduction of the potential for individuals to hold multiple insurance policies. Once individuals are allowed to hold multiple private insurance policies, the private market equilibrium will always be second-best Pareto efficient and government intervention therefore cannot be efficiency-enhancing.

This analysis supports the conclusion of this paper; government intervention in the insurance industry via the ACC scheme results in a loss of consumer and producer welfare that would be otherwise available in the private market.

The competing provider model requires the insurance cover to be specified as a contract and claimants could sue the provider for non-delivery of appropriate services. Claimants under this model would have an incentive to monitor their provider and it would also be more time consistent than the current situation (it is more difficult to breach a contract than it is to change legislation). There are numerous options to solve the problems of a state monopoly provider.

\section{Competition with Multiple State-Owned Providers}

An option for those opposed to private ownership is to establish multiple state-owned providers to compete against each other creating a competitive market while still in government ownership. Some of the benefits of this model include that the providers would behave as full cover insurers and they would be free to respond to consumer demand and facilitate consumer choice. The legislation could also specify a minimum insurance cover, not a maximum. Advantages of a competing State-owned Enterprise (SOE) model are:

16 Charles Wilson "A Model of Insurance Markets with Incomplete Information" (1977) 16 Journal of Economic Theory 167.

17 Amy Finkelstein When can Partial Public Insurance Produce Pareto Improvements? (National Bureau of Economic Research Working Paper Series Number 9035, Washington DC, 2002). 
- Explicit contracts which are enforceable and thus provide greater certainty than a legislated benefit regime;

- Decision-making is decentralised, and consumers receive the benefits of competition for market share among the competing providers;

- Full funding of claims becomes more credible;

- SOEs are subject to the Commerce Act 1986, Fair Trading Act 1986 and Consumer Guarantees Act 1993, so consumers have legal recourse for breach of contract or existing law.

This model has implications for private providers in the insurance market. Competition with SOEs is feasible where as it is impossible under the current regime. The private insurers would have access to the 80 per cent of the personal risk market currently monopolised by the Accident Compensation Corporation. The threat of the SOEs undertaking a broader range of business would be a competitive threat for the private providers.

\section{CONCLUSIONS}

Accidents are just one component of the risk faced by individuals. Separating accident insurance from the broader private insurance market raises costs that are ultimately borne by consumers. In addition, the absence of consumer choice in respect of the insurer and the level of insurance cover (above the minimum level) raises the total cost of the full insurance cover required by individuals. Monopoly provision reduces consumer welfare even when the monopoly is government owned.

The current structure of the accident compensation scheme in New Zealand is inefficient: the perverse incentives and moral hazard problems associated with the scheme are illustrated by the differential between accident rates for employees and the self-employed in the same industries. A scheme that allowed competing providers, and individual and group choice, and that addressed the incentives associated with current scheme, would deliver greater long-term benefits to all potential victims of accidents in New Zealand. 